\title{
EDITORIAL
}

\section{FAVORABLE CONDITIONS FOR THE FUTURE}

The Journal of Surgical Sciences is dedicated to students at medical universities and to young doctors; it has reached its third issue, proving that early enthusiasm and the founders' ambition are equally strong, ensuring a development well worth to dwell our attention upon.

Due to the constant efforts of teachers and students involved in this project we have managed to build a communication platform through which information on medical research can be widely spread, while also maintaining the rigor of medical research and academia.

It is worth recalling the permanent support provided throughout this project by "Carol Davila" University of Medicine and Pharmacy, by the Romanian Student Society for Surgery, by the Circle of Surgical Sciences, as well as by the IASS Association.

Starting with the first issue of the journal, whose release took place in the National Congress of Surgery - Sinaia 2014 we focused on topics of great scientific interest, resulting from thorough investigation of the authors. The first issue of the journal brought together representative works developed within the scientific students' circles, works that have been endorsed during the student sessions of the National Surgery Congress, the National Surgery Conferences and the Congress of Students. The second issue of the Journal of Surgical Sciences expanded the coverage of topics, authors, students, resident physicians and teachers of medical schools in the country who addressed many topics of great interest from a surgical point of view.

With each new page you read in this issue, by means of in-depth studies of the authors coordinated by first hand specialists you will discover new connections that lead towards knowledge.

The accuracy of the information presented, the variety of the topics addressed and the competence of the coordinating authors ensure quality content, which may be included in the scientific reference list of those concerned with broadening their knowledge horizon. With each issue we will strengthen the record of the publication and bring more numerous authors and topics which will whet your interest by means of the peculiarities addressed.

What we want is that this publication should continue to stand for an actual tribune from where both enthusiastic students of the Universities of Medicine and Pharmacy in the country and abroad as well as young doctors interested in surgical sciences can spread valuable information and studies developed with utmost competence. We also intend to put the medical community events in the spotlight and we want to encourage probable initiatives of professionals who believe that they have a say in the field. Authors who wish to make their work known by means of the pages of this journal will be able to see their results printed after meeting the selection criteria established by the editorial staff.

Managing Editor

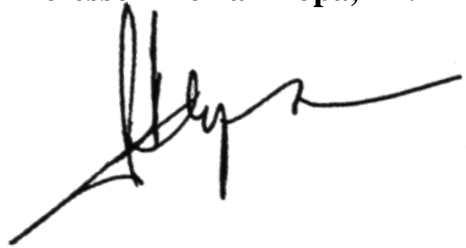

